DOI 10.5216/ia.v46ied.especial.68307

\title{
O PENSAMENTO FREIREANO NAS PESQUISAS EM PROGRAMAS DE PÓS- GRADUAÇÃO EM EDUCAÇÃO NA AMAZÔNIA PARAENSE: DIÁLOGOS NO CAMPO DO CURRÍCULO
}

\author{
JoAna D'ARC de VAsconcelos NeVES \\ JoYCE MARIA DA SILVA CONDE \\ Universidade Federal do Pará (UFPA), Bragança, Pará, Brasil \\ AlessandRa Sampaio CunHa \\ NIVIA MARIA VIEIRA COSTA \\ Instituto Federal de Educação, Ciência e Tecnologia do Pará (IFPA), Bragança, Pará, Brasil
}

\begin{abstract}
REsumo: Este artigo visa evidenciar o pensamento freireano nas discussões sobre currículo em dois Programas de Pós-Graduação em Educação na Amazônia Paraense. A pesquisa do tipo Bibliográfica-Estado do Conhecimento propõe-se a responder: de que forma as concepções de Paulo Freire transversalizam as pesquisas das Teses e Dissertações em diálogos com o campo do currículo? A coleta dos dados foi realizada com o recorte temporal de 2006 a 2018 nos sites dos Programas de Pós-Graduação em Educação UFPA e UEPA. Os resultados apresentam diálogos construídos em três subáreas do currículo: Políticas curriculares, Formação de professores e Práticas educativas curriculares, revelando o pensamento freireano em relação a diferentes questões contemporâneas, comprometidas com a humanização e libertação dos sujeitos amazônidas.
\end{abstract}

Palavras-chave: Currículo. Paulo Freire. Amazônia. Pesquisas em Educação.

INTRODUÇÃO

O presente estudo propôs-se discutir o pensamento freireano, presente nas investigações sobre currículo de pesquisadores do estado do Pará em duas instituições públicas de Ensino Superior, cujo objetivo foi desvelar a presença atuante e marcante de Paulo Freire na Amazônia, especificamente nos programas de Pós-Graduação em Educação.

Paulo Freire é reconhecido como um dos maiores educadores mundiais, patrono da educação brasileira, cujo pensamento social fez com que fosse considerado a voz crítica da educação em relações históricas e culturais opressoras, e defensor da vida e da participação plena das pessoas em sociedade. Trouxe, em suas obras, referências e denúncias sobre processos de opressão-desumanização, criticou as estruturas de dominação causadoras da exploração e apresentou possibilidades de transformação. Representa a defesa da Educação Popular ao estabelecer pressupostos básicos de uma educação ética, politicamente engajada e comprometida com os sujeitos oprimidos.

Em seu construto teórico, Freire (1996) elaborou vários princípios que foram e são fundamentais para a educação crítica, entre eles: a) o homem/mulher como um ser 
de relações, inacabados/as, criadores e transformadores do mundo; b) a educação como ato de conhecimento e transformação de realidades; c) conhecimento emancipador, instrumento de libertação; e d) as culturas como cenários de lutas e contradições, de construção de identidades, alteridade e poder.

Especificamente no campo do currículo crítico, o pensamento freireano contribuiu para refletir o processo educativo a partir dos sujeitos, das relações que se estabelecem em torno do ato educativo, da vida cotidiana na escola e na comunidade, provocando uma ruptura com teóricos que pensam a organização curricular pelo viés dos conteúdos e sob o paradigma da racionalidade técnica.

Em contextos em que a qualidade social da educação tem sido ameaçada por uma lógica mercadológica, o pensamento freireiano ajuda a compreender a necessidade de problematizar o momento vivido e entender os processos educativos em suas dinâmicas. A pedagogia freireana destaca a importância de a educação cumprir o seu papel político, construtora de práticas libertadoras que valorizem a diversidade cultural e o respeito ao outro a partir do diálogo (FREIRE, 1967).

Nessa direção, o presente estudo parte das seguintes indagações: a) de que forma o pensamento freireano transversaliza as pesquisas nos Programas de PósGraduação em Educação, em diálogo com o campo do currículo? b) Quais categorias freireanas são identificadas nesse diálogo?

Assim, buscou-se identificar o pensamento freireano no diálogo com o campo do currículo, nas pesquisas dos dois Programas de Pós-Graduação em Educação na Amazônia Paraense, objetivando visibilizar as contribuições de Paulo Freire para o fortalecimento do currículo crítico na região.

Dessa forma, a intenção de apresentar um olhar sobre as articulações do pensamento freireano, no campo do currículo na realidade educacional amazônica, é para estimular o ato de esperançar freireano que se move em direção à construção da educação pública, na qual a diversidade, autonomia, liberdade, conscientização, diálogo, práxis e ética se configurem como referências para a construção de currículos nas escolas brasileiras.

A seguir, serão apresentados os caminhos metodológicos do artigo, posteriormente, os resultados e as discussões a partir da análise das áreas currículo e do pensamento freireano, bem como suas categorias, presentes nos estudos dos alunos dos programas de Pós-Graduação em Educação do estado do Pará.

\section{MetOdOLOGIA}

O estudo do pensamento freireano nas pesquisas no campo do currículo nos Programas de Pós-Graduação em Educação na Amazônia Paraense aponta para uma pesquisa de caráter bibliográfico, denominado "estado da arte" ou "estado do conhecimento" por apresentar, como descreve Ferreira (2002, p. 258):

[...] o desafio de mapear e de discutir uma certa produção acadêmica em diferentes campos do conhecimento, tentando responder que aspectos e dimensões vêm sendo destacados e privilegiados em diferentes épocas e lugares, de que formas e em 
NEVES, J. A. V.; CONDE, J. M. da S.; CUNHA, A. S.; COSTA, N. M. V.

que condições têm sido produzidas certas dissertações de mestrado, teses de doutorado, publicações em periódicos e comunicações em anais de congressos e de seminários.

Romanowski e Ens (2006, p. 4) defendem que "[...] a análise do campo investigativo é fundamental neste tempo de intensas mudanças associadas aos avanços crescentes da ciência e da tecnologia", na medida em que implica em potencializar e visibilizar o campo teórico do conhecimento de uma determinada área, destacando os aportes significativos que permeiam as produções, lacunas e experiências inovadoras.

Dessa forma, considerando o alcance das pesquisas do "estado da arte" ou "estado do conhecimento", organizou-se este estudo a partir dos seguintes questionamentos: a) de que forma o pensamento freireano transversaliza as pesquisas nos Programas de Pós-Graduação em Educação, em diálogo com o campo do currículo? b) Quais categorias freireanas são identificadas nesse diálogo?

Para atender os objetivos propostos, este estudo foi realizado no ano de 2019, no recorte temporal de 2006-2018 em bancos de teses e dissertações disponibilizados pelos Programas Acadêmicos de Pós-Graduação em Educação da Amazônia Paraense ${ }^{[1]}$, ou seja, nos sites de Pós-Graduação em Educação UEPA (http://ccse.uepa.br); PósGraduação em Educação-UFPA (http://ppgedufpa.com.br); Pós-Graduação em Educação em Currículo e Gestão de Escola Básica-UFPA (http://ppeb.propesp.ufpa.br/index.php/br); e o Pós-Graduação em Educação-UFOPA (http://www.ufopa.edu.br/ppge/index.php?option=com_content\&view=article\&id=17\&l temid=198).

No processo de identificação das teses e dissertações para composição do corpus de análise foram utilizados dois descritores: "Paulo Freire" e "Currículo" de forma intercruzada. No primeiro momento, buscou-se de forma exploratória, no banco de teses e dissertações, a partir do descritor "Paulo Freire" em cada site dos programas e, em seguida, foi realizado individualmente em cada dissertação, a busca do descritor "Currículo".

Ressalta-se que o levantamento, em cada dissertação, foi subsidiado pela análise do discurso com base no dialogismo discursivo de Bakhtin (2011), ou seja, foram considerados a partir do gênero do discurso que configuram as teses e dissertações, e os seus elementos constituintes: título; resumo e palavras-chave; identificando, no conteúdo temático, a existência de interlocuções ao campo do currículo, viabilizando as subáreas estudadas.

Esse processo de cruzamento dos descritores, levou a um recorte do lócus a dissertações em apenas dois programas de Pós-Graduação, visto que os demais programas, no momento do estudo, não apresentavam produções a partir do cruzamento do critério dos interlocutores. Conforme Tabela 1 que segue:

Tabela 1 - Pesquisa exploratória do corpus de análise

\begin{tabular}{l|l|l}
\hline PROGRAMAS & DISSERTAÇÕES & TESES \\
\hline
\end{tabular}




\begin{tabular}{c|c|c}
\hline Pós-Graduação em Educação-UEPA & 06 & 0 \\
\hline Pós-Graduação em Educação-UFPA & 05 & 0 \\
\hline $\begin{array}{c}\text { Pós-Graduação em Educação em Currículo e } \\
\text { Gestão de Escola Básica-UFPA }\end{array}$ & 0 & 0 \\
\hline Pós-Graduação em Educação-UFOPA & 0 & 0 \\
\hline Total & 11 & 0 \\
\hline
\end{tabular}

Fonte: Autoras (2020).

Identificada as 11 dissertações que compuseram o corpus desta pesquisa, realizou-se a análise qualitativa - reflexões das formas pelas quais os autores das dissertações teceram a interlocução entre o pensamento freireano e o currículo, com base no princípio dialógico de Bakthin (1988). Nesse processo, os enunciados (fragmentos de trechos extraídos das dissertações) configuram-se como elo na cadeia da enunciação e, como tal, foram compreendidos como uma abstração, um recorte do real, possibilitando, dessa forma, identificar as reflexões e articulações do pensamento freireano ao campo no currículo nas Dissertações e Teses nos Programas de Educação na Amazônia Paraense.

\section{RESULTADOS E DISCUSSÃO}

Articular a epistemologia do pensamento freireano ao campo educacional, especificamente ao currículo, tem se configurado como resistência a concepções restritas e fragmentadas de pensar o currículo como programas uniformizadores e de programação de conteúdo. Nessa perspectiva, trazer 'à tona' a forma como os pesquisadores dialogam com a teoria freireana contribui para ampliar a compreensão da multidimensionalidade do fenômeno educativo, assim como destacar a importância do construto freireano e dos movimentos de elaborações de propostas curriculares que visam à formação para emancipação humana.

Assim, no processo de busca das pesquisas, que estabeleceram a relação entre o pensamento freireano ao campo do currículo, foram identificadas e catalogadas 11 produções acadêmicas, sendo 6 (seis) dissertações na Universidade do Estado do Pará (UEPA) e 5 (cinco) dissertações na Universidade Federal do Pará (UFPA) e nenhuma tese.

No sentido de demonstrar a vivacidade e atualidade dessas contribuições, assim como articulá-las à perspectiva de análise do discurso com base no dialogismo discursivo, foram realizados dois processos de categorizações que levou à identificação tanto das subáreas do currículo quanto das categorias freireanas. Assim, as subáreas do campo do currículo identificadas: políticas curriculares; formação de educadores e currículos; práticas educacionais curriculares, apontam para um vasto campo de possibilidades no debate do currículo subsidiado por categorias freireanas, como: 
NEVES, J. A. V.; CONDE, J. M. da S.; CUNHA, A. S.; COSTA, N. M. V.

libertação, dialogicidade, conscientização, politicidade, comprometimento, práxis e ética, conforme Tabela 2 que segue.

Tabela 2 - Áreas e categorias identificadas

\begin{tabular}{c|l}
\hline SUBÁREAS DO CAMPO DO CURRÍCULO & \multicolumn{1}{c}{ CATEGORIAS FREIREANAS } \\
\hline Políticas Curriculares & $\begin{array}{l}\text { Libertação } \\
\text { Dialogicidade } \\
\text { Conscientização }\end{array}$ \\
\hline Formação de educadores e currículos & $\begin{array}{l}\text { Politicidade } \\
\text { Comprometimento }\end{array}$ \\
\hline Práticas educacionais curriculares & $\begin{array}{l}\text { Práxis } \\
\text { Ética }\end{array}$ \\
\hline
\end{tabular}

Fonte: Autoras (2020).

São dissertações que apresentam categorias que, para além da crítica ao modelo de educação vigente, visam demonstrar ser possível e desejável romper com modelos educativos opressores, na direção de construir uma práxis em que as escolas tenham autonomia e os sujeitos tenham vozes.

Nas interlocuções sobre Paulo Freire e currículo, identificou-se que os pesquisadores articularam diálogos a partir de diferentes temáticas, focos e sujeitos diferenciados, evidenciando diversidades amazônicas educacionais não estáticas e em movimentos de resistências, enfrentamentos e transformações de realidades. Conforme a Tabela 3 a seguir:

Tabela 3 - Produções acadêmicas sobre Freire e Currículo - Categorias de Análises

\begin{tabular}{c|l|c}
\hline \multicolumn{3}{|c}{ POLITICAS CURRICULARES } \\
\hline $\begin{array}{c}\text { AUTOR(A) } \\
\text { /ANO }\end{array}$ & \multicolumn{1}{|c}{ TíTULO } & INSTITUIÇÃO \\
\hline $\begin{array}{c}\text { OLANDA } \\
(2006)\end{array}$ & $\begin{array}{l}\text { O currículo em uma classe hospitalar: estudo de caso no } \\
\text { Albergue Pavilhão São José da Santa Casa de Misericórdia do } \\
\text { Pará }\end{array}$ & UFPA \\
\hline $\begin{array}{c}\text { GOÉS } \\
(2009)\end{array}$ & $\begin{array}{l}\text { Educação popular em ambiente hospitalar: construção de } \\
\text { identidades como processo de afirmação cultural }\end{array}$ & UEPA \\
\hline $\begin{array}{c}\text { PINHEIRO } \\
(2009)\end{array}$ & $\begin{array}{l}\text { Currículo e seus significados para os sujeitos de uma escola } \\
\text { ribeirinha, multisseriada no município de Cametá-Pará }\end{array}$ & UFPA \\
\hline $\begin{array}{c}\text { JUNIOR } \\
(2010)\end{array}$ & $\begin{array}{l}\text { Meio ambiente e ética: entrecruzando olhares no ensino de } \\
\text { ciências }\end{array}$ & UFPA \\
\hline
\end{tabular}

Inter-Ação, Goiânia, v. 46, n. ed.especial, p. 1206-1223, set. 2021. Disponível em: <http://dx.doi.org/10.5216/ia.v46ied.especial.68307>. 


\begin{tabular}{|c|c|c|}
\hline $\begin{array}{l}\text { MATOS } \\
(2015)\end{array}$ & $\begin{array}{l}\text { Educadores populares freireanos: um olhar para as práticas } \\
\text { educativas }\end{array}$ & UEPA \\
\hline $\begin{array}{l}\text { BARBOSA } \\
(2018)\end{array}$ & $\begin{array}{l}\text { O ensino de filosofia e a formação do ser-sujeito-criança na } \\
\text { educação de Paulo Freire }\end{array}$ & UFPA \\
\hline \multicolumn{3}{|c|}{ FORMAÇÃO DE PROFESSORES E O CURRÍCULO } \\
\hline $\begin{array}{l}\text { FERREIRA } \\
(2007)\end{array}$ & $\begin{array}{l}\text { A formação dos professores: saberes e práticas de letramento } \\
\text { na educação de jovens e adultos }\end{array}$ & UEPA \\
\hline $\begin{array}{l}\text { SILVA } \\
(2008)\end{array}$ & $\begin{array}{l}\text { Formação continuada e a prática educativa dos professores (as) } \\
\text { da educação de jovens e adultos do município de Colares-PA }\end{array}$ & UEPA \\
\hline $\begin{array}{l}\text { FONSECA } \\
(2011)\end{array}$ & $\begin{array}{l}\text { Formação sociopolítica da universidade popular (UNIPOP): } \\
\text { fundamentos e contribuições da educação popular na } \\
\text { formação delideranças sociais }\end{array}$ & UEPA \\
\hline \multicolumn{3}{|c|}{ PRÁTICAS PEDAGÓGICAS CURRICULARES } \\
\hline $\begin{array}{l}\text { MELO } \\
(2007)\end{array}$ & $\begin{array}{l}\text { A prática pedagógica e a construção de saberes do biólogo no } \\
\text { ensino da física em ciências na } 8^{a} \text { série }\end{array}$ & UFPA \\
\hline DIAS (2012) & $\begin{array}{l}\text { Paulo Freire na escola cabana: memórias e práxis de } \\
\text { profissionais da educação de jovens e adultos }\end{array}$ & UEPA \\
\hline
\end{tabular}

Fonte: Autoras (2020).

A partir das categorias freireanas identificadas nas dissertações que se relacionavam ao currículo, discutiu-se os trechos das pesquisas, as áreas do currículo nas quais se evidenciaram e o pensamento de Paulo Freire, presente em cada uma delas. Como subtítulo, considerou-se as três áreas do currículo, a saber: Políticas curriculares; Formação de professores e currículo; e Práticas pedagógicas curriculares.

\section{PolítICAS CURRICULARES}

As produções que apresentam os estudos sobre as Políticas curriculares focam o debate articulando o currículo a duas categorias centrais: Crítico-Libertador e a Cultura. Ao relacionar o currículo na visão Crítico-Libertador, os autores apresentam reflexões sobre práticas educativas contra-hegemônicas.

Nessa direção, a assunção dos princípios curriculares libertadores emerge na reflexão da educação em ambientes hospitalares (OLANDA, 2006; GOÉS, 2009), em ambientes escolares (BARBOSA, 2018; PINHEIRO, 2009; BARBOSA JUNIOR,2010), assim como na educação popular (MATOS, 2015).

Cabe ressaltar que os referidos autores apresentam em seus trabalhos a educação como prática libertadora, cujo objetivo da aprendizagem se constitui no 
NEVES, J. A. V.; CONDE, J. M. da S.; CUNHA, A. S.; COSTA, N. M. V.

processo de tomada de consciência, ou seja, uma educação voltada para a promoção da criticidade por meio do processo de escolarização. Os enunciados extraídos das dissertações, apresentados a seguir, reafirmam a presença do pensamento freireano.

Para aprender ler e escrever fundamentado por uma postura do currículo crítico, Freire (2006) propõe como alternativa pesquisar o universo cultural dos sujeitos e no contexto educativo provocando a descoberta dos temas significativos para não somente alfabetizar os educandos, mas para explorar os conhecimentos significativos construídos pela humanidade, despertando nestes o senso crítico. (PINHEIRO, 2009, p. 154).

Uma das grandes máximas freireanas é que o ensino presta-se a promover a assunção humana, para que cada ser humano se assume como ser pensante, crítico, curioso e conhecedor. Para que isto se concretize é fundamental que se não se negue possibilidades para que este ser humano, este ser sujeito, e tratando aqui das crianças tenham seu direito à vida respeitado. (BARBOSA, 2018, p. 74).

A partir dos escritos cabe a reflexão em torno da categoria da libertação que, no método educativo e dialético, preconizado por Paulo Freire, o ser humano é o agente protagonista, pois é sujeito de relação no/com o mundo, e com os outros. Ou seja, é sujeito da busca de conhecimento, do desconhecido, de se aventurar para transformar e fazê-lo, assumindo, assim, sua condição de ser político, militante, uma vez que já não se satisfaz em apenas assistir, quer também participar (FREIRE, 1970).

Logo, ter liberdade, na concepção freireana, necessita do ser humano o exercício da capacidade de pronunciar o mundo. $O$ ser humano deve assumir uma posição frente à sociedade e à realidade em que vive, no sentido de ultrapassar o nível da consciência real, atingindo, dessa maneira, a consciência possível, uma vez que tudo é possível de ser transformado, quando se refere às situações e práticas criadas pela humanidade (FREIRE, 1967).

Os autores que utilizam o referencial teórico do currículo crítico-libertador apresentam, em seus escritos, a ideia de que ele oferece parâmetros para pensar e concretizar a política educacional, pois consiste em um paradigma de compreensão e de intervenção na realidade a partir de uma educação compromissada com o processo humanizador. Em síntese, a compreensão do currículo crítico libertador caracteriza-se como defesa de uma política complexa e relacional de vários elementos que articulam, de modo coerente, princípios e conceitos teóricos práticos, necessários para que se realize a crítica e a ruptura do paradigma curricular hegemônico, e concretize modelos escolares, marcados por práticas e relações que promovam eticamente a vida humana nas suas mais diferentes necessidades e potencialidades.

As produções que focalizam o currículo e a cultura destacam que essa articulação torna o currículo uma dimensão humanista, tendo na cultura a referência para as mudanças de atitudes dos sujeitos e da própria realidade. Ressalta-se que Freire (1963), na obra Conscientização e Alfabetização: uma nova visão do processo, já destacava a cultura como fundamental no exercício de se compreender criticamente no mundo: 
A cultura como acrescentamento que o homem faz ao mundo que ele não fez. A cultura como resultado de seu trabalho. De seu esforço criador e recriador. O homem, afinal, no mundo e com o mundo, como sujeito e não como objeto. [...] descobrir-se-ia criticamente agora, como fazedor desse mundo da cultura. Descobriria que ele, como o letrado, ambos têm um ímpeto de criação e recriação. Descobriria que tanto é cultura um boneco de barro feito pelos artistas, seus irmãos do povo, como também é a obra de um grande escultor, de um grande pintor ou músico. Que cultura é a poesia dos poetas letrados do seu país, como também a poesia do seu cancioneiro popular. Que cultura são as formas de comportar-se. Que cultura é toda criação humana. (FREIRE, 1963, p. $10)$.

Nessa direção, as dissertações de Goés (2009) e Barbosa Junior (2010) destacam a ideia do sujeito crítico, como um fazedor do mundo da cultura, visto que ele tem dentro de si a criação e recriação do mundo em que está inserido, uma vez que "[...] a identidade, então, se constitui nas inter-relações entre a atividade e a consciência de cada ser humano, inseridas em contextos socioculturais" (GOÉS, 2009, p. 55), ou ainda, do papel do currículo escolar em envolver os elementos sociais e culturais pois "[...] a escola não poderia desenvolver um processo educativo de forma mecânica, apenas dentro de quatro paredes, sem considerar e envolver os elementos sociais e culturais que tanto influenciam a vida dos sujeitos" (BARBOSA JUNIOR, 2010, p. 31).

A centralidade da articulação da cultura ao currículo, nos trabalhos referenciados por Freire (1963), configura-se na necessidade de destacar: a) o conhecimento significativo da realidade vivida; b) os conhecimentos presentes no imaginário criativo expressos nas linguagens e identidades dos sujeitos; c) nas formas de resistência coletivamente construídas em diferentes experiências, conforme as dissertações de Goés (2009) e Barbosa Junior (2010).

Nesse contexto, destaca-se a categoria freireana da dialogicidade que consiste no diálogo com respeito às diferenças de ideias e de posições quanto à necessidade humana de comunicação social. Diante disso, o diálogo torna-se fundamental, na medida em que se caracteriza como

[...] o encontro dos homens, mediatizados pelo mundo, para pronunciá-lo, não se esgotando, portanto, na relação eu-tu. Esta é a razão por que não é possível o diálogo entre os que querem a pronúncia do mundo e os que não querem; entre os que negam aos demais o direito de dizer a palavra e os que se acham negados deste direito. (FREIRE, 2005, p. 91).

A relação dialógica estabelece uma relação horizontal, e não vertical, entre as pessoas. Dessa maneira, o saber de todos os sujeitos deve ser valorizado, visto que é na relação que a produção do conhecimento ganha sentido, como apresenta Freire (1967). A partir da reflexão que o homem faz sobre sua posição no mundo, sobre o mundo, sobre seu trabalho, sobre seu poder de transformar o mundo, é que o conhecimento 
NEVES, J. A. V.; CONDE, J. M. da S.; CUNHA, A. S.; COSTA, N. M. V.

deixa de ser algo externo ao homem e começa a fazer parte do próprio homem, em um movimento relacional com outros homens e com a cultura. O processo de conhecer 0 mundo, na perspectiva freireana, envolve, como descreve Olanda (2006), a capacidade da escuta sensível para desmitificar a aparência e compreender que a complexidade opressora é marcada por múltiplas formas, pelas culturas e pelos interesses diversificados de todos que constituem a classe multisseriada do espaço hospitalar.

\begin{abstract}
Trabalhar a "realidade vivida" pelos alunos-pacientes do Pavilhão São José é uma questão complexa, não pelo fato de pertencerem a Municípios diferentes e se encontrarem inseridos numa realidade adversa provocada pela doença mas, principalmente, pelas experiências de insucesso escolar que geram desinteresse pela construção ou reconstrução do conhecimento e tessituras de saberes, pela complexidade social pertencente a cada um, pelas culturas e pelos interesses diversificados de todos que constituem essa classe multisseriada. A falta de estabelecimento de diálogo entre as culturas presentes nesta classe hospitalar fez com que os sujeitos desse processo educativo deixem de perceber o valor de cada cultura nos mais diversos espaços. (OLANDA, 2006, p. 99).
\end{abstract}

Nesse sentido, esta pesquisa destaca a importância do diálogo entre educação e cultura, sustentando a tese que essa relação possibilita a construção do novo conhecimento. Isto significa dizer que, na lógica do pensamento freireano, o conhecimento configura-se como resultado da investigação que 'nasce' da relação entre o currículo e a realidade, garantindo que ele seja realmente significativo entre educandos e educadores.

Para que não seja uma mera descrição de realidade, os autores defendem a articulação entre o currículo e a cultura. Trata-se de um mecanismo de compreender a realidade sob uma nova ótica, no sentido de romper com visões ingênuas, conforme trecho da dissertação de Matos (2015, p. 65) ao afirmar que "[...] a transformação da sociedade na qual se constrói um novo ser humano e uma nova cultura ocorre num processo permanente e coletivo, em que as classes populares possam se educar com sua própria prática e fortalecer os seus saberes como base na educação popular".

A categoria da conscientização surge nos discursos de Matos (2015), ressaltando a lógica do pensamento freireano de que a consciência humana ocorre a partir do jogo dialético das relações homem-mundo. Relações em que consciência e mundo ocorrem simultaneamente, uma vez que, de acordo com Freire (1992),

[...], não há eu que se constitua sem um não eu. Por sua vez, o nãoeu constituinte do eu se constitui na constituição do eu constituído. Desta forma, o mundo constituinte da consciência se torna um mundo da consciência, um percebido objetivo seu, ao qual se intenciona. (FREIRE, 1992, p. 71).

Logo, ao fazer essa afirmação, Paulo Freire (1992) refere-se à constituição do ser dentro da dimensão ontológica, estabelecendo a relação a uma função cultural histórica como sujeito de ação relacional com outros seres e com a natureza. Uma lógica que coloca o ser humano para além de sua dimensão biológica, como um ser social, 
constitui-se na relação com os outros, ao mesmo tempo em que produz cultura. Nessa direção, aponta-se para a existência ontológica da igualdade humana, reafirmada na capacidade produtora de cultura que impede o estabelecimento de graus de valores diferenciados para as culturas construídas.

\section{FORMAÇÃO DE EDUCADORES E CURRÍCULO}

As dissertações que pesquisaram a Formação de professores e currículo trazem como temáticas a formação permanente e a formação sociopolítica na perspectiva da educação popular. Destacaram que Freire discutiu amplamente a formação de educadores, inspirado em sua experiência de diálogos com educadores de vários países e, também, a partir de suas convicções sobre a relevância da formação no ato de educar, a exemplo do que ocorreu quando atuou na Secretaria Municipal de Educação de São Paulo (SME-SP).

[...] um dos programas prioritários em que estou profundamente empenhado é o de formação permanente dos educadores, por entender que os educadores necessitam de uma prática políticopedagógica séria e competente que responda à nova fisionomia da escola que se busca construir. (FREIRE, 2001, p. 80).

Para Freire (2001), a formação necessita ser pautada na reflexão crítica sobre a prática, que permita o processo de ação-reflexão, desenvolvendo no sujeito uma postura crítica frente à realidade do seu tempo. Esse pensamento corresponde à visão da formação como capaz de transformar, de provocar mudanças na educação brasileira. Trata-se de uma compreensão na qual a formação visa a uma prática que favoreça a autonomia, por meio da estimulação da curiosidade epistemológica e da construção da consciência da necessidade de posicionar-se diante da realidade, superando posturas ingênuas no contexto social.

Nesses estudos, defende-se a premissa de que a formação não se esgota em si mesma, ela deve ter um caráter permanente com a função de articular a formação inicial e as mudanças, tanto no interior da escola quanto também no sistema escolar. Nos dizeres de Freire (2001):

A melhora da qualidade da educação implica a formação permanente dos educadores. $\mathrm{E}$ a formação permanente se funda na prática de analisar a prática. É pensando sua prática, naturalmente com a presença de pessoal altamente qualificado, que é possível perceber embutida na prática uma teoria não percebida ainda, pouco percebida ou já percebida, mas pouco assumida. (FREIRE, 2001, p. 72).

A capacidade de analisar a própria prática como elemento qualificador da ação docente é inscrita no campo da formação de professores como práxis, envolve investimentos que articula a formação profissional docente à formação humana, visando 
NEVES, J. A. V.; CONDE, J. M. da S.; CUNHA, A. S.; COSTA, N. M. V.

potencializar práticas que atendam às demandas sociais, como apresentada pelos autores nos excertos extraídos nas dissertações:

É necessário compreendê-las como um investimento pessoal, profissional, institucional, político, público, social e econômico. Acrescento mais, precisam, sobretudo, serem compreendidas dentro de uma dimensão de formação humana, estética e ética. (SILVA, 2008, p. 35).

A formação docente não deve objetivar apenas formar profissionais versáteis, adaptáveis e flexíveis, conforme a necessidade do mercado, mas principalmente deve visar formar profissionais que atendam às demandas sociais. (FERREIRA, 2007, p. 118).

Assim, ao analisar os anunciados sobre a formação docente, identificou-se a categoria da politicidade, pois Freire (1967) ressalta que não há e nem jamais houve prática educativa em espaço e tempo nenhum, de tal maneira neutra. Segundo Paulo Freire (1967), somos seres históricos, constituídos e transformadores, ou seja, sujeitos capazes de modificar tudo e todos que passaram pela nossa trajetória de vida. Dessa maneira,

[...] é na diretividade da educação, esta vocação que ela tem, como ação especificamente humana, de endereçar-se até sonhos, ideais, utopias e objetivos, que se acha o que venho chamando politicidade da educação. A qualidade de ser política, inerente à sua natureza. (FREIRE, 1967 p. 110).

Inerente ao exercício do trabalho docente, a qualidade política está presente no trabalho de cada professor, nas formas pelas quais as concepções de educação orientam suas práticas docentes. Nessa perspectiva, a discussão acerca da formação docente deve ser pensada tanto nas instituições de ensino superior quanto nas escolas de educação básica e por meio de políticas públicas para a carreira do professor (FREIRE, 1992).

Assim, a valorização dos saberes dos sujeitos no processo de formação, contribuindo para (re)pensar a prática social, constitui-se a partir da problematização da realidade: "[...] é que a realidade opressora, ao constituir-se como um quase mecanismo de absorção dos que nela se encontram, funciona como uma força de imersão de consciência" (FREIRE, 1970, p. 21). Nessa perspectiva Fonseca (2011), em sua dissertação, afirma que:

A educação problematizadora é o processo formativo de caráter popular e é intencionalmente vinculado a um projeto de emancipação dos sujeitos e que nesse processo os saberes estão contidos e outros emergem, constituindo-se como base para a construção deste projeto e possibilitando que os sujeitos tomem consciência da sua condição de sujeito histórico. (FONSECA, 2011, p. 94).

Fonseca (2011) ainda enfatiza, a partir de seus escritos, a categoria do comprometimento, uma vez que se centra na indissociabilidade freireana entre as ideias 
e a ação, apontando, enquanto primeira condição, como ato de compromisso a capacidade docente de agir e refletir, "[...] sua tendência é refletir sobre sua própria situacionalidade, na medida em que, desapoiados por ela, agem sobre ela" (FREIRE, 1970, p. 58).

Logo, a formação sociopolítica é constituída por uma conexão permanente entre a teoria e a prática, buscando trazer informações históricas e teóricas para que os educadores sejam capazes de realizar reflexões políticas e conscientes que os auxiliem em suas lutas sociais. Para Gohn (2005), esse tipo de educação envolve aprendizagem política dos direitos dos cidadãos, gera consciência para compreensão de seus interesses e de sua realidade local, nacional e internacional, resultando na participação, ao articular práticas coletivas e organização comunitária.

Esse tipo de formação gera forças sociais organizadas, pois existe uma intencionalidade dos sujeitos em criar e alcançar seus objetivos que têm caráter coletivo. Desse modo, a participação política resulta no fortalecimento da prática social e revela a participação democrática dos sujeitos.

\section{PRÁtICAS PEDAGÓGICAS CURRICULARES}

As dissertações que destacaram as Práticas educativas curriculares trouxeram como foco a prática pedagógica e a construção de saberes, assim como as memórias e a práxis, salientando que os educadores necessitam continuamente refletir sobre sua ação docente para que possam ter maior aproximação entre teoria e prática, conhecimento e realidade. Melo (2007) e Dias (2012), ao tratarem sobre o currículo, apresentam Freire para esclarecer que a verdadeira reflexão crítica origina-se e dialetiza-se na interioridade da práxis constitutiva do mundo humano. Nas palavras de Freire (1970):

\footnotetext{
[...] se os homens são seres do que fazer é exatamente porque seu fazer é ação e reflexão. É práxis. É transformação do mundo. E, na razão mesma em que o que fazer é práxis, todo fazer do que fazer tem de ter uma teoria que necessariamente o ilumine. O que fazer é teoria e prática. É reflexão e ação. (FREIRE, 1970, p. 77).
}

Nessa direção, as pesquisas destacam que o ponto de partida da prática educativa é a situação concreta, a realidade. A experiência prática torna-se a referência do momento reflexivo, práxis. Nos diferentes contextos educacionais, a prática docente deve gerar nos educandos a curiosidade por meio de pesquisas e das trocas de saberes, reconfigurando, assim, o próprio currículo.

Para tanto, são necessárias práticas contextualizadas, que percebam o cotidiano dos educandos como um meio favorável para a educação, sendo necessário adentrar no cotidiano dos alunos para iniciar um processo educativo favorável com aulas mais dinâmicas, criativas, significativas e menos tradicionais, como destacam Dias (2012) e Melo (2007) nos trechos que seguem:

Prática educativa humanizadora, portanto, com referência na tolerância como qualidade de conviver, respeitar e aprender com o 
NEVES, J. A. V.; CONDE, J. M. da S.; CUNHA, A. S.; COSTA, N. M. V.

diferente (FREIRE, 1997a). Prática que parte das expectativas e da realidade material dos educandos para efetivar seu planejamento pedagógico curricular. (DIAS, 2012, p. 126).

Percebemos, todavia, que nossa formação inicial está muito voltada para as questões teóricas, com leituras e reflexão de textos que falam sobre a docência, enquanto a verdadeira prática ainda caminha distante da formação de professores. Inserir na prática educativa valores sociais referentes a comunidade influencia, sobremaneira na prática escolar. (MELO, 2007, p. 22).

Ao tratarem da "verdadeira prática", "prática educativa humanizadora", conforme essas citações, Melo (2007) e Dias (2012) acionam a categoria freireana da ética, relacionando-a a ideia de educar à alteridade, ao respeito, ou seja, a necessidade do colocar-se no lugar do outro como condição necessária para a práxis freireana, uma vez que,

É no respeito às diferenças entre mim e eles ou elas, na coerência entre o que faço e o que digo, que me encontro com eles ou com elas. E na minha disponibilidade à realidade que construo a minha segurança, indispensável à própria disponibilidade. É impossível viver a disponibilidade à realidade sem segurança, mas é impossível também criar a segurança fora do risco da disponibilidade. (FREIRE, 1996, p. 135).

Nesse contexto, a troca de saberes entre os educadores e os educandos geram a construção e reconstrução dos saberes de ambos. Freire (1996) afirma que os educandos vão se transformando em reais sujeitos da construção e da reconstrução do saber ensinado, ao lado do educador, igualmente sujeito do processo por meio de postura reflexivas e dialéticas de suas ações.

Nessa direção, refletir criticamente os processos relacionais e dialógicos que realizam-se no contexto de sala de aula é fundamental ao trabalho docente, na medida em que essas reflexões potencializam práticas melhores que as anteriores. Uma postura dialética que envolva ação-reflexão-ação, caracterizada por Freire (1992) de práxis educativa, em que o professor busque realizar atividades que contribuam tanto para uma melhor aprendizagem dos educandos quanto para melhor prática do educador, mediada pela reflexão das práticas anteriores.

Desse modo, para uma boa prática de ensino e aprendizagem, os educadores precisam buscar sua própria libertação e trabalhar na libertação junto aos educandos, mas para que isso ocorra, eles contam com o poder da palavra como instrumento essencial no processo de aprender e ensinar.

Assim, a partir das produções analisadas foi possível identificar que os estudos, referentes ao currículo, evidenciam que o pensamento político-pedagógico de Paulo Freire está sempre em movimento e constante diálogo com diferentes questões contemporâneas, logo, traz elementos norteadores para a construção da teoria curricular emancipatória e comprometida com a humanização e libertação dos sujeitos. 


\section{CONSIDERAÇÕES FINAIS}

Ao longo deste estudo, buscou-se compreender e analisar as formas pelas quais o pensamento freireano transversalizam as pesquisas das Teses e Dissertações em diálogos com o campo currículo nos programas de educação na Amazônia Paraense.

Ressalta-se que a perspectiva crítica de Freire embasou a transversalidade dos diálogos dos autores das dissertações, articulados a três subáreas do currículo: Políticas curriculares; Formação de professores e Práticas educativas curriculares, revelando o pensamento freireano em movimento crítico-reflexivo analítico com as diversidades e territorialidades educativas dos sujeitos amazônidas. São diálogos que se colocam a favor da humanização e da emancipação dos sujeitos em diferentes contextos de práticas educativas escolares e hospitalares, destacando, a partir das experiências estudadas, os conflitos e as contradições em que os sujeitos e as práticas educativas estão inseridos.

Na transversalização entre o pensamento freireano, as subáreas do currículo: Políticas curriculares, Formação de educadores e currículos, Práticas educacionais curriculares; as categorias freireanas: libertação, dialogicidade, conscientização, politicidade, comprometimento, práxis e ética emergem para subsidiar as escrituras de currículo crítico em defesa de práticas educativas humanizadoras, considerando as diversidades de sujeitos e as condições de existências. Principalmente, reconhecendo os alunos como sujeitos cognoscentes do processo educativo liberto dos condicionantes deterministas, impostos pela ideologia dominante.

As contribuições para a educação na Amazônia Paraense, das dissertações investigadas no Programa de Pós-Graduação em Educação, ocorrem na medida em que promovem a superação da compreensão de um currículo tradicional que nega o contexto social e cultural dos povos da Amazônia, evidenciando a necessidade da existência de um currículo reflexivo, político e transformador, que não apenas contribua para uma nova visão acerca da questão curricular, mas apresente caminhos para uma construção de uma sociedade mais justa e fraterna, com igualdade de condições para todas as pessoas e povos tradicionais que nela habitam.

Artigo recebido em: 23/03/2021

Aprovado para publicação em: 29/06/2021

FREIREAN THOUGHT IN POSTGRADUATE PROGRAMS IN EDUCATION IN THE PARAENSE AMAZON: DIALOGUE IN THE CURRICULUM FIELD

ABSTRACT: This article aims to highlight the freirean thought in the discussions about curriculum in the Postgraduate Programs in Education in the Paraense Amazon. The Bibliographic State of Knowledge research proposes to answer: in which way Paulo Freire's conceptions transversalize the research of Theses and Dissertations with the curriculum field? Data collection was carried out in the time frame from 2006 to 2018 on the websites of the UFPA and UEPA Education Programs. 
NEVES, J. A. V.; CONDE, J. M. da S.; CUNHA, A. S.; COSTA, N. M. V.

The results show dialogues built in three sub-areas of the curriculum: Curriculum Policies; Teacher training; Curriculum educational practices, revealing Freirean thought in movement together with different contemporary issues committed to the humanization and liberation of Amazonian individuals.

KEYWORDS: Curriculum. Paulo Freire. Amazon. Researches about Education.

PENSAMIENTO FREIREANO EN EDUCACIÓN PROGRAMAS DE GRADUADO EN LA AMAZONIA DEL PARAENSE: DIÁLOGO EN EL CAMPO DEL CURRÍCULO

RESUMEN: Este artículo tiene como objetivo resaltar el legado freireano en las discusiones sobre currículum en los Programas de Posgrado en Educación en la Amazonía Paraense. La investigación tipo Bibliográfico-Estado del Conocimiento se propone responder: ¿Cómo cruzan las concepciones de Paulo Freire la investigación de Tesis y Disertaciones en diálogo con el campo curricular? La recolección de datos se realizó con el marco temporal de 2006 a 2018 en los sitios web de los Programas Educativos de la UFPA y UEPA. Los resultados muestran diálogos construidos en tres subáreas del currículo: Políticas curriculares; Formación de profesores; Prácticas educativas curriculares, revelando el pensamiento freireano en movimiento con diferentes problemáticas contemporáneas comprometidas con la humanización y liberación de los sujetos amazónicos.

PALABRAS CLAVE: Plan de Estudios. Paulo Freire. Amazonas. Investigación en Educación.

\section{REFERÊNCIAS}

BARBOSA, C. M. B. O ensino de filosofia e a formação do ser-sujeito-criança na educação de Paulo Freire. 2018. Dissertação (Mestrado em Educação) - Programa de Pós-Graduação em Educação, Universidade Federal do Pará, Belém, 2018.

BARBOSA JUNIOR, I. R. Meio ambiente e ética: entrecruzando olhares no ensino de ciências. 2010. Dissertação (Mestrado em Educação e Ciências Matemática) Instituto de Educação Matemática e Científica, Universidade Federal do Pará, Belém, 2010.

BAKHTIN, M. Marxismo e filosofia da linguagem: problemas fundamentais do método sociológico na ciência da linguagem. $4^{\mathrm{a}}$ ed. Tradução de Michel Lahud e Yara Frateschi Vieira. São Paulo: Hucitec, 1988.

BAKHTIN, M. Estética da criação verbal. Tradução de Mariana Appenzellerl. 6a ed. São Paulo: Martins Fontes, 2011. 
DIAS, A. S. Paulo Freire na escola cabana: memórias e práxis de profissionais da educação de jovens e adultos. 2012. Dissertação (Mestrado em Educação) - Programa de Pós-Graduação em Educação, Universidade Estadual do Pará, Belém, 2012.

FERREIRA, I. S. B. A formação dos professores: saberes e práticas de letramento na educação de jovens e adultos. 2007. Dissertação (Mestrado em Educação) - Programa de Pós-Graduação em Educação, Universidade Estadual do Pará, Belém, 2007.

FERREIRA, N. S. A. As pesquisas denominadas "estado da arte". Educação \& Sociedade, Campinas, s/v, n. 79, p. 257-272, ago. 2002. Disponível em: <Rev79_06REV\&SINT (scielo.br)> Acesso em: 20 fev. 2021.

FREIRE, P. Pedagogia do oprimido. 23. ed. Rio de Janeiro: Paz e Terra, 1970.

FREIRE, P. Educação como prática da liberdade. Rio de Janeiro: Paz e Terra, 1967.

FREIRE, P. Conscientização e alfabetização: uma nova visão do processo. Manuscrito de Paulo Freire. $1963 . \quad$ Disponível em: $<$ https://nepegeo.paginas.ufsc.br/files/2018/11/Paulo-FreireConscientiza\%C3\%A7\%C3\%A3o-e-alfabetiza\%C3\%A7\%C3\%A3o-Uma-novavis\%C3\%A3o-do-processo.pdf >. Acessado em: 20 fev. 2021.

FREIRE, P. Política e educação: ensaios. 6. ed. São Paulo: Cortez, 2001.

FREIRE, P. A educação na cidade. São Paulo: Cortez, 2005.

FREIRE, P. Pedagogia dos sonhos possíveis. São Paulo: Editora UNESP, 1997.

FREIRE, P. Pedagogia da autonomia: saberes necessários à prática educativa. 22. ed. São Paulo: Paz e Terra, 1996.

FREIRE, P. Professora sim, tia não: cartas a quem ousa ensinar. São Paulo: Olho d' Água, 1992.

FONSECA, S. F. Formação sócio política da Universidade Popular (UNIPOP): fundamentos e contribuições da educação popular na formação de lideranças sociais. 2011. Dissertação (Mestrado em Educação) - Programa de Pós-Graduação em Educação, Universidade Estadual do Pará, Belém, 2011.

GÓES, W. M. C. Educação popular em ambiente hospitalar: construção de identidades como processo de afirmação cultural. 2009. Dissertação (Mestrado em Educação) Programa de Pós-Graduação em Educação, Universidade Estadual do Pará, Belém, 2009. 
NEVES, J. A. V.; CONDE, J. M. da S.; CUNHA, A. S.; COSTA, N. M. V.

GOHN, M. G. Educação não-formal e cultura política: impactos sobre o associativismo do terceiro setor. São Paulo: Cortez, 2005.

MELO, L. A. R. A prática pedagógica e a construção de saberes do biólogo no ensino da física em ciências na $8^{a}$ série. 2007. Dissertação (Mestrado em Educação) Programa de Pós-Graduação em Educação, Universidade Estadual do Pará, Belém, 2007.

MATOS, L. L. S. Educadores populares freireanos: um olhar para as práticas educativas. 2015. Dissertação (Mestrado em Educação) - Programa de Pós-Graduação em Educação, Universidade Estadual do Pará, Belém, 2015.

OLANDA, O. F. J. O currículo em uma classe hospitalar: estudo de caso no albergue pavilhão São José da Santa Casa de Misericórdia do Pará. 2006. Dissertação (Mestrado em Educação) - Programa de Pós-Graduação em Educação, Universidade Estadual do Pará, Belém, 2006.

PINHEIRO, M. S. D. Currículo e seus significados para os sujeitos de uma escola ribeirinha, multisseriada no município de Cametá-Pará. 2009. Dissertação (Mestrado em Educação) - Programa de Pós-Graduação em Educação, Universidade Estadual do Pará, Belém, 2009.

ROMANOWSKI, J. P.; ENS, R. T. As pesquisas denominadas do tipo "Estado da Arte". Diálogos Educacionais, Curitiba, v. 6, n. 6, p. 37-50, 2006

SILVA, M. J. L. Formação continuada e a prática educativa dos professores (as) da educação de jovens e adultos do município de Colares - PA. 2008. Dissertação (Mestrado em Educação) - Programa de Pós-Graduação em Educação, Universidade Estadual do Pará, Belém, 2008.

JoAna D'arC de Vasconcelos NeVes: Doutora e Mestra em Educação pela Universidade Federal do Pará. Atualmente é Docente do Programa de Pós-Graduação Linguagens e Saberes da Amazônia e professora Adjunta da Universidade Federal do Pará, Campus de Bragança-Pa.

Orcid: https://orcid.org/0000-0002-3110-3649

E-mail: jdneves@ufpa.br

Joyce Maria da Silva Conde: Mestranda em Linguagens e Saberes da Amazônia pelo Programa de Pós-Graduação em Linguagens e Saberes da Amazônia (PPLSAVUFPA). Licenciada em Pedagogia pela Universidade Federal do Pará (UFPA). Membro do Grupo de pesquisa de Educação de Jovens e Adultos e Diversidade na Amazônia (GUEAJAJUFPA) e da Cátedra Paulo Freire na Amazônia.

Orcid: https://orcid.org/0000-0002-0727-240X

E-mail: joycecondeufpa@gmail.com 


\author{
Alessandra Sampaio Cunha: Doutorado em Ciências da Educação. Técnica em \\ Assuntos Educacionais do Instituto Federal de Educação, Ciência e Tecnologia do Pará - \\ IFPACCampus Bragança. Membro da Cátedra Paulo Freire na Amazônia. \\ Orcid: https://orcid.org/0000-0001-7504-3185 \\ E-mail: alessandra.sampaio@ifpa.edu.br \\ Nivia Maria Vieira Costa: Pós doutora em Educação de Adultos - Universidade de \\ Coimbra. Doutora em Educação (UFC). Professora do Instituto Federal de Educação, \\ Ciência e Tecnologia do Pará - IFPAVCampus Bragança. Membro da Cátedra Paulo \\ Freire na Amazônia. \\ Orcid: https://orcid.org/0000-0003-1077-8011 \\ E-mail: nivia.costa@ifpa.edu.br
}

Este periódico utiliza a licença Creative Commons Attribution 3.0, para periódicos de acesso aberto (Open Archives Initiative - OAI). 